\title{
TOWARDS A 3D CADASTRE: WHERE DO CADASTRAL NEEDS AND TECHNICAL POSSIBILITIES MEET?
}

\author{
JANTIEN STOTER $^{1}$ AND MARTIN SALZMANN ${ }^{2}$
}

${ }^{1}$ Delft University of Technology, Department of Geodesy

${ }^{2}$ Kadaster (Cadastre and Public Registers Agency of the Netherlands) The Netherlands

\section{Abstract}

In the Dutch cadastral registration a cadastral object (real-estate object) is by definition 2D (a parcel). In intensively used areas there is a tendency to use space above and under the surface, e.g. constructions on top of each other, infrastructure above/under the ground, increasing number of cables and pipes, apartments above shops/offices/other apartments.

These factual 3D objects cannot be defined as cadastral objects in the cadastral map, which is based on $2 \mathrm{D}$ parcels, and cannot be used as a base for registration. From a juridical point of view the current registration has proved to be still sufficient in those situations. However, the Netherlands' Kadaster wants to assure a sustainable, uniform and efficient registration in the future. Therefore, a research is carried out at the Department of Geodesy in collaboration with the Netherlands' Kadaster to develop a prototype of a land information system that can take the relevant $3 \mathrm{D}$ information into account.

This paper is written as part of our joint research. Starting points are the needs of the Netherlands' Kadaster on the one hand and the technological possibilities on the other hand. We are looking for a concept in which cadastral needs and technical possibilities meet.

The most feasible solution for this is to start with the current 2D cadastral registration and to extend this with a $3 \mathrm{D}$ implementation for the registration of $3 \mathrm{D}$ situations. The realisation of this concept is described in this paper. 


\section{INTRODUCTION}

The Netherlands' Kadaster is responsible for maintaining the public registers and the cadastral registration (including the cadastral map) concerning real estate.

In major urban centres (and especially their business districts), land use is becoming so intense, that different types of 'land' use are being positioned under and above each other. This puts the practicality of the currently used concept of 2D cadastral parcels to the limit. Examples of existing 3D situations are:

- constructions on top of each other;

- infrastructure above and under the ground;

- the increasing number of cables and pipes (as well as the increasing number of owners of cables and pipes due to privatisation processes);

- apartments.

These factual 3D objects cannot be defined as a cadastral object in the cadastral map and cannot be used as a base for registration. The only realworld objects on the cadastral map are (the contours of) buildings, which serve as a reference framework for the orientation.

From a juridical point of view the current registration is still sufficient to register the right of property of real-world objects. The Kadaster is however more and more confronted with the limitations of the current registration possibilities to register spatially complex property rights. Moreover, the Kadaster wants to assure a sustainable, uniform and efficient registration in the future and thus looks for better ways to register 3D situations.

Therefore, a research is carried out at the Department of Geodesy, Delft University of Technology in collaboration with the Netherlands' Kadaster to study the issue of $3 \mathrm{D}$ cadastral registration in a fundamental way. The aim is to develop a prototype of a land information system that can take the relevant $3 \mathrm{D}$ information into account.

This paper is written as part of our joint research. Starting points are the envisaged need of the Netherlands' Kadaster for an improved 3D registration while taking into account the existing registrations on one hand and the technological possibilities on the other hand. We start with an example of the current practise of the registration of a 3D situation. Than the cadastral needs and ambitions are described, in which three possible solutions are given. These solutions are criticized both from a cadastral point of view and a technical point of view. This leads to a concept of the most optimal solution for a 3D cadastre. The technical realisation of this concept is described. Finally these realisations are applied to the previous described case. 
Related work can be found in Stoter and Zevenbergen, 2001 and Doytsher et al., 2001.

\section{Example of CurRent Practise}

Figure 1 shows an example of a 3D real-world situation.
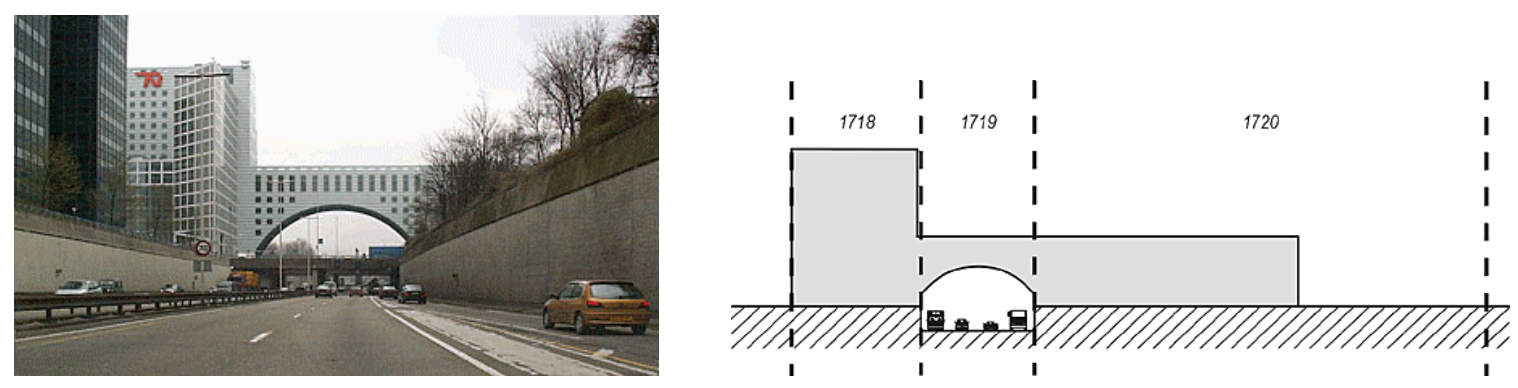

Figure 1: One objects (building), three parcels.

Three parcels are needed to register the right of property of the building (Figure 1, right). On the cadastral map (Figure 2) you can see the contours of the building and the surface parcels.

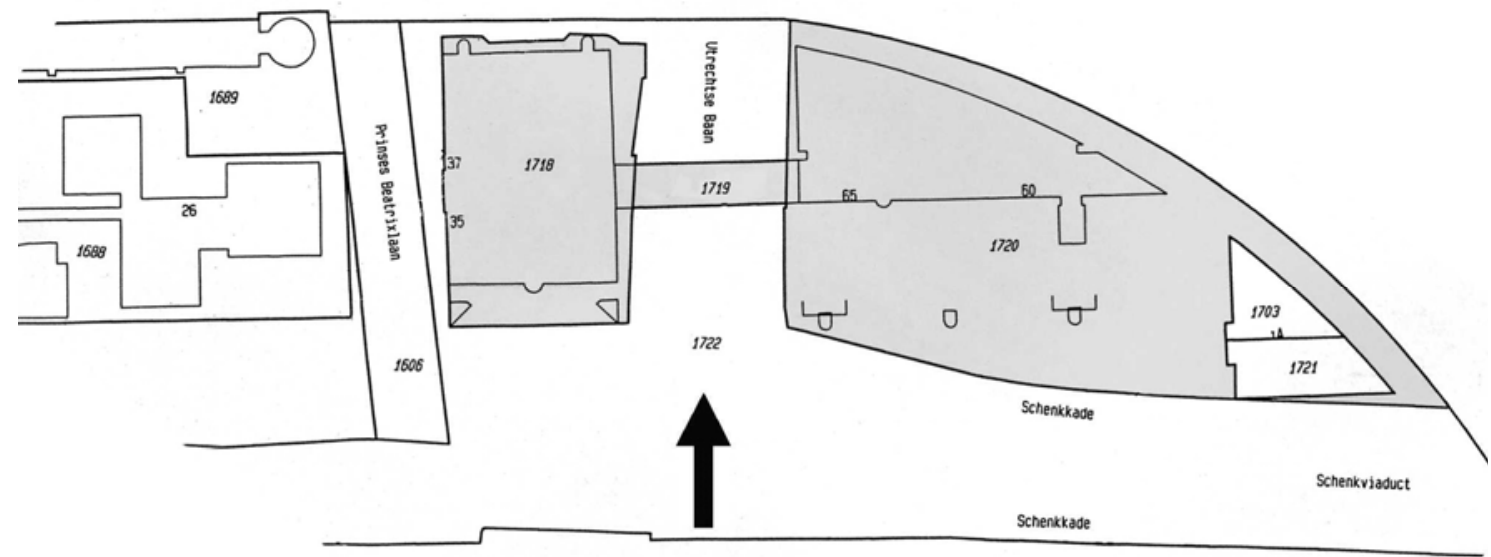

Figure 2: Cadastral map of a construction above the surface (see figure 1).

The arrow indicates the view position of the camara in Figure 1 (left). The firm 'Nationale Nederlanden' possesses the whole building. The rights and restrictions of the parcels concerned are as follows. The municipality holds a restricted property on parcels 1719 and 1720. 'Nationale Nederlanden' 
possesses an unrestricted property on parcel 1718, a right of building on parcel 1719 and a right of long lease on parcel 1720.

\section{CADASTRAL NEEDS AND AMBITIONS}

This section describes the issue of $3 \mathrm{D}$ cadastral registration from a cadastral point of view, starting with the current situation. Needs, possible solutions and ambitions are described, followed by considerations how to maintain 3D situations.

\section{Starting from the current cadastral registration...}

\section{Current situation}

Legal objects in the Netherlands are by definition 2D and all rights on real estate are based on these premises. According to the Dutch Civil Code (1992), the right of property of a parcel is not limited in the vertical dimension and hence the property extends to the centre of the Earth and into the sky. The only exception is that use of space above and under the surface is permitted to third persons, as long as this is done as high or as low, that there is no sense for the owner to object against this use.

A juridical horizontal division in land use can only be established by the registration of limited rights on the $2 \mathrm{D}$ surface parcel (without linking explicit height values to the parcels) such as right of building, limitations according to Administrative Law, right of long lease (Stoter, 2000). In some cases, it is even necessary to create new parcels on the surface to be able to define the legal status in 3D satisfactorily. The deed, which is at the basis of the registration, may be accompanied by a drawing, which is very useful in (complex) situations. Mostly a drawing is included to clarify a situation, i.e. the drawing provides additional insight. The drawing may describe legal boundaries if it is part of the deed. Drawings are mandatory for the establishment of the right of condominium. In this case the lay-out of the drawings is even prescribed by law. Height is not an element of the specifications. These drawings do not infringe the concept of the 2D legal object, but clarify the internal subdivision of rights. In all cases other than condominium rights the lay-out of the drawings is not prescribed. Note that these drawings are not (yet) digital.

\section{Need for a 3D cadastre}

Currently all complex situations are (and can be) registered based on 2D legal objects (see the previous example). Therefore a $3 \mathrm{D}$ solution is not necessary from a strictly legal and cadastral point of view. The purpose of the Kadaster, however, is to provide legal security concerning real estate. That requires that also complex 3D situations should be identifiable and their registration should be accessible. At the moment the accessibility of the 
registration in $3 \mathrm{D}$ situations is poor. At first sight even the professional (notary, real-estate agent or cadastral employee) may not be aware of a 3D situation; let alone the public at large and the non-cadastral-specialists (e.g. planners and contractors). It is therefore mainly from an information point of view that there exists a need for a better insight in 3D-situations. The better the accessibility of the registration in complex 3D situations, the better the legal security of the real estate is warranted. Another aspect is the consistency and redundancy of the data: e.g. in the case of a pipeline every parcel that intersects with the pipeline has the information of the pipeline and its impeder associated with it.

\section{Possible solutions}

Starting from the existing registration one could register 3D situations in the following manner:

1. A full 3D cadastral registration as a final solution

This means introduction of the concept of (property) rights in 3D space. The legal basis, real estate transaction protocols and the cadastral registration should support the establishment and conveyance of 3D rights. From a practical point of view it seems best to maintain the 2D parcel as default; only in complex 3D situations the full 3D parcel would be used. It might also be considered if a limited definition of 3D property rights would fulfil a need (e.g. one or more property layer(s) underground or above ground level and one at ground level).

2. A hybrid solution

This means preservation of the $2 \mathrm{D}$ cadastre and the registration of the factual situation in $3 \mathrm{D}$ by registering $3 \mathrm{D}$ objects within the $2 \mathrm{D}$ cadastral registration. This results in a hybrid solution of $2 \mathrm{D}$ parcels and $3 \mathrm{D}$ factual objects in which the explicit relationships between the parcels and the $3 \mathrm{D}$ objects are maintained. Implicit relationships exist through the spatial definition of the objects and can be retrieved by spatial functions. In this case the legal and factual registrations are combined (hybrid solution). By intersection of e.g. a building plan with the cadastral parcels indications of the 3D property rights can be derived. The exact legal situation has to be derived from the official documents. These documents then have to contain precise 3D information.

3. 3D tags in the current cadastral registration system

This means preservation of the $2 \mathrm{D}$ cadastre with references to representations of (digital) 3D situations. Complex 3D situations are registered using ad hoc solutions. This is the current situation. The reference can be made in various ways. The simplest solution is to tag 3D situations in the registration (administrative register and the cadastral index map) whereupon the user then has to consult the (digital) public registers to find the detailed information. A more advanced option is to add a reference to a $3 \mathrm{D}$ (digital) description in the registration. The 
description may be available in analogue or digital form (e.g. a CADdrawing). In the latter case the information might even be included in the database. Relevant are the possible formats (scanned, DGN, DXF, etc.). The projected contours of the 3D (physical) object could also be registered in the cadastral map.

These solutions are applicable to situations under and above the ground.

In practice most 3D situations have been registered using condominium rights or the right of building. In the case of condominium rights information is available using the legally prescribed drawings. Although not strictly 3D, a drawing of each vertical layer is provided. In case a right of building is established generally no drawings are available.

In the case of tunnels the above lying parcels are expropriated so that the holder of the tunnel becomes the right of property of the concerning parcels. Sometimes the right of building is given back to the former owners (RAVI, 2000).

Lately a solution has been implemented for objects underground (tunnels etc.). It corresponds basically to the last possible solution sketched above. It consists of a notification in the administrative registration of the existence of an underground object. The deed, which has led to the registration, may be accompanied by an analogue drawing. The contours of the underground object may be depicted in the cadastral map. The inclusion of digital 3D drawings is not possible at the moment.

In practice the use of this solution has been limited. Notaries have to get used to this new type of registration. They will use it when it has clear benefits to them or their customers (e.g. more legal security, less work).

The limited use of this solution is also partly due to the fact that many underground situations relate to infrastructure where the owner of the parcel is also the owner of the underground object (e.g. a subway-tunnel under land owned by the municipality). In those cases often no reference to an underground object is made at all in the deed, let alone that a drawing is provided!

A quick scan in July 2001 revealed that in the Netherlands 67 cases of underground objects are registered and that none of these cases is indicated on the cadastral map.

\section{How to proceed}

The best strategy for the future seems to be a step-by-step approach. First the awareness of a 3D registration should be enhanced. The (voluntary) registration of 3D situations should be promoted. The better 3D situations are registered, the better the legal status of real estate is guaranteed through better accessibility. At the same time we expect that the demand for 3D 
information will grow. The experience with the (proven) registration of condominium rights and the created possibilities to register underground objects are good starting points.

Secondly emerging best working practices can become default standards once the number of ' $3 \mathrm{D}$ registrations' increases. In our experience 'industry standards' are a very useful starting point for formal standardisation and technical (cadastral) regulations. At this point also the methodology (input formats, working processes and technology) of registration can be refined. Finally, when the 3D registration has reached acceptance a full 3D cadastre can be considered (option 1, above), including its legal implications.

\section{Maintaining 3D situations}

For the time being registration of 3D situations will remain voluntary (except condominium rights). This makes the registration of $3 \mathrm{D}$ situations incomplete by definition. Increasing the awareness by promoting the benefits of 3D information and the expected increasing demand, will lead to a growing $3 \mathrm{D}$ registration.

There exist no guidelines or specifications how to provide 3D information. The registrars promote the inclusion of drawings for the clarification of complex situations, but as long as legal conditions are fulfilled, they cannot demand additional information concerning the 3D situation. In the future standardisation of the format of the drawings should be considered. It would be practical if the (analogue or digital) drawings meet at least certain minimal requirements.

In the current situation the paper (3D) drawings are filed in the public registers with the accompanying deed and in the registration reference is made to the 3D situation. Our experience with condominium rights shows that this is a workable, albeit not perfect, solution. At the time of writing the Kadaster is beginning to scan incoming deeds. If drawings are supplied on A4-paper format they are also scanned, but this basically keeps the information analogue. Unfortunately most maps are on larger paper formats.

The Kadaster cannot enforce standardisation by its own, although it has an important role in the discussion. It can issue a number of guidelines for the submission of $3 \mathrm{D}$ information (based on best practices). Once the number of 3D objects registered increases, more effort can be put in the actual format of the 3D registration. Slowly this would result in more consistency in the registration. 


\section{Cadastral Registration and Three Dimensions: THREe Possible SOLUTIONS}

Considering the ever-increasing demand for 3D information in complex situation basically the following options are possible, as was seen before:

- full 3D

- hybrid

$-3 \mathrm{D}$ tags

In this section these solutions are criticised both from a cadastral point of view and a technical point of view.

\section{A cadastral view on the proposed solutions}

\section{Full 3D}

A full 3D approach would result in a complete renewal of the cadastral registration. From a legal point of view, first the concept of 3D legal objects needs to be introduced. This requires a change of law (civil code), which is a very lengthy process. The discussion on how a 3D legal object is defined could (and probably will) take years. Issues that are involved in this discussion are (Stoter and Zevenbergen, 2001):

- The meaning of the right of property has to be reconsidered: should the right of property of a $2 \mathrm{D}$ parcel be defined as a column of space less the possible existence of a 3D parcel above or under the surface?

- Are the owners of 'surface' parcels obliged to tolerate the definition of a 3D parcel above or under their parcel (they loose an amount of 'space' of their property)? Compare this to the right of building in $2 \mathrm{D}$.

- What happens if a 3D property volume moves due to subsidence of the construction?

- Juridical relations between parcels on top of each other should be clearly defined like access to the concerning parcels via other parcels (right of easement in 3D space?) as well as the protection (avoiding damage) of the real estate objects involved.

Furthermore, from a practical point of view, a 3D cadastre is useful in densely built-up areas. For most of the country, however, a 'classical' 2D cadastre based on parcels serves its purpose well. Therefore the Kadaster will not opt for a full 3D cadastre in the short to medium near future.

\section{Hybrid}

The approach where $3 \mathrm{D}$ objects are stored in the $2 \mathrm{D}$ cadastral registration is a very promising one. It is very advantageous from the point of view of accessibility. Both the $2 \mathrm{D}$ and $3 \mathrm{D}$ information is available directly and can be combined automatically. A practical bottleneck in the short term is the 
existing data model of the registration, which is $2 \mathrm{D}$. Point of attention is that users should be aware that the registration of 3D factual objects is not identical to the definition of 3D legal objects.

\section{D Tags in the current cadastral registration}

This approach is followed at the moment, apart from the fact that we do not store the 3D situations separately in the database as so-called 'local' files but on paper drawings. It has proven to be practical with condominium rights. There seems no reason why it should not be feasible for other 3D situations. Given the current cadastral data models this option seems to be a good starting point, but is not a practical solution in the medium to long run as was concluded before. For the future accessibility it would be beneficial if some rules of thumb are developed (based on best practice) on how to describe and store 3D situations.

Overall the current 2D cadastral registration system based on 2D parcels still suffices in many cases. In addition there are large amounts of data in 2D available at the Kadaster. Therefore it is a realistic solution to start with the current cadastral registration system based on $2 \mathrm{D}$ parcels and to extend this when the situation requires this.

\section{A technical view on the proposed solutions}

\section{Full 3D}

The spatial registration of rights in 3D seems to be the final and most advanced solution. Therefore a 3D spatial model is needed. The development of 3D models and the representation should be considered, as well as the availability and the effort that it takes to collect the required data (3D parcel geometry and topology) to make the developed system operational. We can learn form large-scale 3D city models.

Incorporating the developed concepts into present systems and working processes is also an important factor for consideration.

Such a system might be a solution in the future. However, at the moment this solution is not realistic considering the current status of technological implementations in this area.

\section{Hybrid}

The combination of $2 \mathrm{D}$ and 3D data in one geo-DBMS, including storage, access, query and analysis, offers the facility to take the juridical relevant spatial information in the vertical dimension into account when the situation requires this.

Besides the spatial representation of 3D geo-objects in the current 2D geoDBMS, attributes of these objects will also be maintained in the DBMS, as well as the rights and limited rights concerning these objects. These rights 
contain the explicit relationships between the 3D geo-objects and the 2D parcels.

This solution is also a very challenging one concerning technological aspects. However, it is a more realistic solution than the first one and therefore interesting for further research.

\section{D Tags in the current cadastral registration}

A less interfering solution to register $3 \mathrm{D}$ situations is to maintain the current registration and to use ad-hoc solutions in complex 3D situations and thereby have references to the representation of the actual situation (digital or analogue).

In case of a cable or pipeline with the right of property registered by a right of building a reference will be maintained to a (by preference 3D) representation of the actual location of the cable. The difference with the previous solution is that the database contains references to paper drawings or digital files outside the DBMS, instead of integrating the 3D objects in the $2 \mathrm{D}$ geo-DBMS. The problem of this solution is that the DBMS cannot guarantee consistency, nor can the $3 \mathrm{D}$ object be queried in a combined environment with the $2 \mathrm{D}$ parcels.

\section{Where cadastral needs and technical possibilities meet}

In conclusion, the option 'a $2 \mathrm{D}$ cadastral registration system with references to 3D situations' does not give a base for efficient and sustainable registrations in the future. On the other hand, a full 3D cadastre is too comprehensive and is something to be considered in the faraway future. It is more efficient to focus on an achievable solution in the nearby future. Therefore, the most feasible solution is to start with the current $2 \mathrm{D}$ cadastral registration and to extend this with a 3D implementation for the registration of $3 \mathrm{D}$ situations. This is the concept where we expect that cadastral needs and technical possibilities will meet. In the next section the technical realisation of this concept is described.

\section{THE REALISATION OF A 3D CADASTRE}

A '3D cadastral system' is now defined as a system, which still registers rights and limited rights on 2D parcels, but which gives more insight in the juridical and factual situation above and under the surface in case this is relevant with respect to legal security. This insight is obtained through spatially defining constructions on, above and under the surface as $3 \mathrm{D}$ geoobjects in the currently used cadastral system. Whether these objects will be defined as juridical objects is a subject that runs parallel to this research. Juridical developments can be influenced by technological possibilities. Recommendations can be done for the registration of $3 \mathrm{D}$ situations to 
support the uniformity, consistency, clarity and with that the maintainability of registrations.

The current information system that is used by the Netherlands' Kadaster consists of (Lemmen et al., 1998):

- a 2D geo-DBMS for maintaining the geometry and topology of parcels (and buildings for reference purpose) called LKI ('Information system for Surveying and Mapping')

- an administrative DBMS for legal and other administrative data related to parcels called AKR ('Automated Cadastral Registration')

A link between those two subsystems exists through the unique parcel number. The geo-DBMS and the administrative DBMS will be used as starting point and will be extended with possibilities to maintain 3D objects.

\section{The administrative data model}

The current administrative model is based on three key types: object, subject and right (see Figure 3). Objects are parcels and condominium rights which are linked to a 'mother' parcel. Subjects are legal persons with rights on parcels.

Objects and subjects have a n:m relationships via rights: a subject can have rights related two more than one object (e.g. a persons owns three parcels) and one object can be related to more than one subject (e.g. one subject is bare owner of a parcel and another subject has the right of building on the parcel) (Oosterom et al., 2000 (1)).

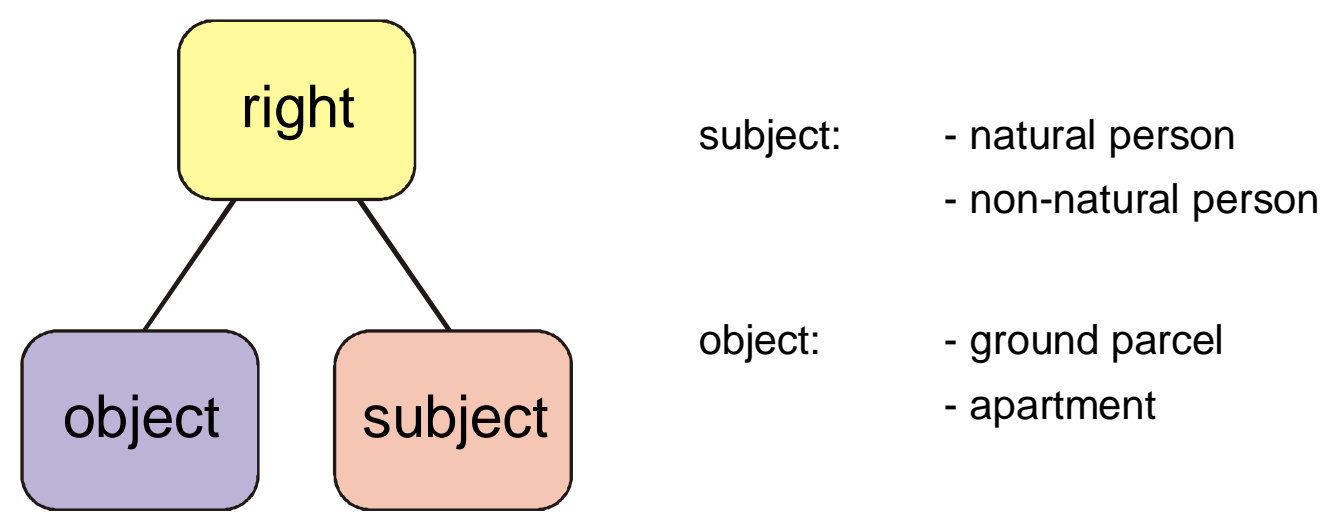

Figure 3: The current administrative logical data model: object, subject and right.

To be able to register 3D situations separate from parcel objects 3D factual objects (real-world objects) must also be defined as cadastral objects, together with the holders of these objects. 
The holder of a 3D world object is the organisation or person who is responsible for the object and uses the object as if he were the owner.

In the case of real-world objects under or above the surface, a few cases can be distinguished:

- the holder of the object is the full owner of the surface parcel(s);

- the holder of the object is the bare owner of the surface parcel(s): other subjects have also certain types of rights on the parcel, such as right of building, right of long lease, right of easement etc.;

- the holder of the object is not the owner of the surface parcel but has limited rights on the parcel, such as right of building or a right according to Administrative Law;

- the holder of the object is not the owner of the surface parcel and has no rights on the parcel: the legal status of the real-world object is not explicitly registered.

It is evident that the last case should be avoided.

The proposed data model is illustrated in Figure 4.

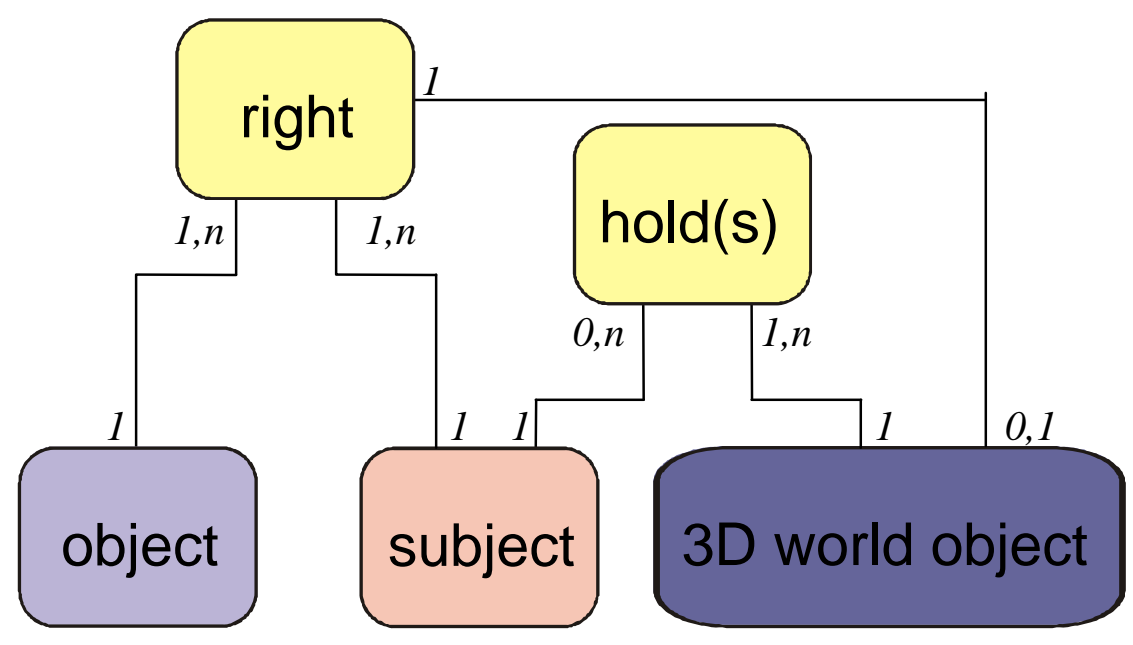

Figure 4: The administrative relationships between 2D parcels, subjects and 3D objects.

Juridical explicit relationships between a 3D world object and the surface parcels exist through the holders of the 3D world object who are subjects of rights on parcels. The rights are not established directly on a 3D worldobject but associated with a 3D world object stored with the concerning rights. This means that a holder (subject) always has a right on a parcel. The possible relations between $3 \mathrm{D}$ world objects on the one hand and parcels on the other hand are: $1-1,1-n, n-1$ or $m-n$ via rights. For example one object 
can intersect with several parcels and one parcel can intersect with more than one 3D object.

The possible relations between 3D world objects on the one hand and subjects on the other hand are: $1-1,1-n, n-1$ or $m-n$ via the holdrelationship. For example one $3 \mathrm{D}$ object can have more than one holder, and one holder can hold more than one 3D object.

\section{D Spatial definition}

The 3D real-world object must be spatially defined in the current geoDBMS, in which topological as well as geometric aspects are important. The incorporation of 3D features in the DBMS based on 2D parcels consists of implicit as well as explicit relations:

- topological structure will preferably be maintained explicitly (e.g. bodies, faces, edges, nodes), because of data consistency checks;

- topological relations between two arbitrary objects will preferably be maintained implicitly, built in the geometric data model. These relations can be derived by means of geometry functions and operators and can be used in constraints (e.g. to avoid overlaps);

- juridical relations will be maintained explicitly (see previous section).

Note that when topological relations between objects are 'derived on the fly' the accuracy of the data is very important (when are objects inside, touching, equal, overlapping?). This is the case in $2 \mathrm{D}$, but much more complicated in 3D.

The spatial implementation of 3D geo-objects in a DBMS is complex and depends on technological developments. An ideal case would be the use of 3D geometric data types available in a DBMS, having the DBMS to maintain topology (2D and 3D) and to perform spatial functions in $2 \mathrm{D}$ and $3 \mathrm{D}$ at the SQL level.

A full functional support of the topology of geographical objects within the DBMS is needed, because it enables (Oosterom et al., 2000 (2)):

- to check correctness (after edit operations), e.g. common boundaries;

- to facilitate complex operators in 3D (map overlay, split/merge operations);

- to maintain consistency;

- to use topological structure in spatial queries;

- to integrate (store and query) 2D data and 3D data.

Many concepts have been developed in this area (e.g. see Molenaar, 1990; Pigot, 1995; Pilouk, 1996; Kofler, 1998; Saadi Mesgari, 2000; Zlatanova, 2000). These concepts are increasingly being implemented in mainstream DBMSs. 


\section{The state of the art}

In 2D mainstream DBMSs (Oracle, IBM DB2, Informix, Ingres) have implemented spatial data types and spatial functions more or less similar to the OpenGIS Consortium (OGC, 1998) Simple Features Specification for SQL (OGC, 1999). The purpose of this specification is to define a standard SQL extension that supports storage, retrieval, query and update of simple spatial features. Topological relationships between objects can be retrieved by the use of spatial functions. Topological management of structures (partitions) is not available within DBMSs. OGC specifications (OGC, 2001) are till now 2D, although efforts are being made to extend these to 3D.

In this research Oracle Spatial (9i) is used for prototype implementations of 3D situations. The supported spatial features in Oracle are point, line and polygons (including arcs, box and sets). Z-values can be used to represent 3D features (3D points, 3D lines and 3D polygons), but 3D models are not supported: topological structures are not recognised (this is also true in 2D), nor can spatial objects in 3D be represented and manipulated. An experiment in Oracle (version 9i) showed that the z-value, defined in a 3D geometry type is not used in spatial queries. As a consequence of the lack of topology 3D (and 2D) neighbours cannot be detected.

\section{The current geo-DBMS based on $2 D$ parcels as starting point}

The current method to define (2D) parcels will be used as starting point. In the geometric database of the Kadaster the boundaries of parcels are geometrically defined. Parcels themselves are topologically defined using the parcel and boundary table (Oosterom and Lemmen, 2001). The parcel table contains a reference to the first edge of every ring (to the outer ring and possibly to one or several inner rings). The edges (a straight line or a circular arc) in the boundary table contain references to other edges according to the winged edge structure (Baumgart, 1975), which are used to form the complete boundary chains (Figure 5).

The 3D data model will be used to represent the relevant spatial properties of real-world objects, which is the bounding envelope. The bounding envelope can be defined by the outer and inner boundaries while disregarding internal details.

The initial preference was to define the geometric volume primitive for the 3D cadastral data model in analogy with the representation of geo-objects in the 2D cadastral data model (point, line and/or circular arc and polygon, described by a sequence of lines or arcs) and to use these spatial features in $2 \mathrm{D}$ as the base in $3 \mathrm{D}$. The $3 \mathrm{D}$ primitives would therefore preferably be composed of polyhedrons, spheres, cones and cylinders. 


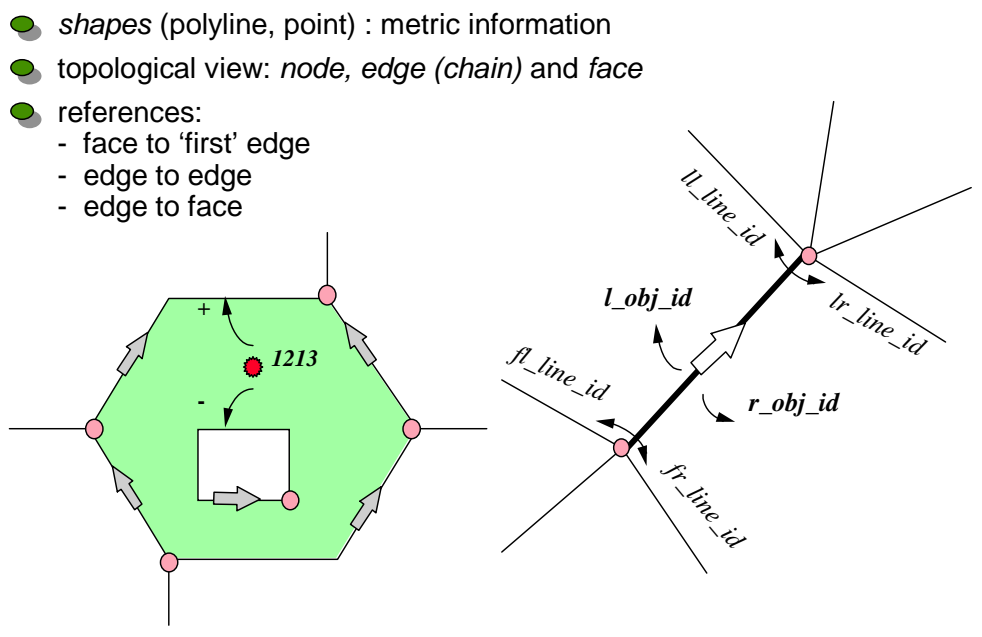

Figure 5: Topology model in the spatial DBMS of the Kadaster.

However, implementation experiments showed that those primitives are still complex. For example, in 2D, a circular arc can be inserted and defined with a starting point, a radius and a point on the circle. What points do you need for sphere-patches? Although one could find points for this, it is hard to maintain this data model and complicated to survey and input these points (which points are exactly needed?). Therefore first only polyhedrons will be used to spatially define 3D real-world objects in the DBMS.

Polyhedrons are solids, bounded by flat surfaces with each surface bounded by straight lines. Note that it may be difficult to describe a polyhedron correctly, as the four or more 3D points of a face do not always lie in a flat surface. Before the 3D spatial data is stored in the DBMS, it should therefore be checked if the surfaces are flat enough within a given tolerance. Non-flat surfaces are more or less undefined which is not desirable in cadastral situations for 3D boundary faces.

\section{Implementation of a $3 D$ spatial model}

Given the current technological possibilities and the current 2D geo-DBMS, the 3D data model is implemented in two ways in order to look for the best design solutions:

1. using self containing 3D geometric data types and topology only within objects;

2. creating a topological model between objects to maintain and retrieve 3D objects. 
Implementation experiments will have to show which model is better for the purpose to register 3D cadastral situations.

\section{Using $3 D$ geometric data types}

As was mentioned before, 3D (volumetric) data types are future work for Oracle. Still you can use the advantages of the other spatial data types (3D polygons), which are supported by defining a 3D geo-object as a complex object consisting of a polyhedron with references to the faces it consists of. The faces are stored as 3D polygons. This model is partly a topological model, since the body is defined by references to the faces.

With this solution it is possible to retrieve 2D topological relations between (the projection of) 3D objects and surface parcels. Once 3D spatial functions are available, also 3D relations can be retrieved. Another advantage is that the 3D faces are recognised by GIS and CAD applications that can make a database connection by means of a geometry column in a DBMS. In this way it is possible to visualise (and edit) the data in a GIS or CAD with 3D capabilities. At the moment this possibility is tested with Microstation, as well as concepts to extend the current spatial model in Oracle to support 3D volumetric data types.

\section{Creating a topological model}

As was mentioned before, DBMSs do not (yet) support topology (2D nor 3D). Therefore, a topological model has to be defined in a DBMS by means of user-defined references. A topological model for 3D geo-objects is currently developed at the Department of Geodesy of the Delft University of Technology (Zlatanova, 2001). A 3D geometry object is therein defined as a polyhedron consisting of nodes and faces. This topological model is used in this research and implemented on top of Oracle. The model consists of 3 tables: BODY, FACE and NODE and each table contains references to other tables: the BODY-table contains references to the faces and the FACE-table contains references to the nodes (with their co-ordinates).

Disadvantages of using a self-made topological model are:

- using topology in querying can be very difficult at SQL level (topology is not recognized by DBMSs). For spatial queries it is always required to generate a realisation of the object. Therefore an extension is needed or own spatial functions have to be implemented in PL/SQL, instead of being able to use the spatial queries available in the DBMS (although 3D spatial queries are not yet available in DBMS's);

- the data model is complicated and no standards exist for a topological data model;

- since the DBMS does not recognise topology, the consistency of the data has to be checked by other software.

This option is also tested for the cadastral data. 


\section{Integration of $2 \mathrm{D}$ parcels and $3 \mathrm{D}$ objects}

The maintenance of implicit and explicit relationships between objects above and under the surface with the parcels on the surface completes the incorporation of $3 \mathrm{D}$ objects in the current cadastral system. By these relations it is possible to query the data $2 \mathrm{D}, 3 \mathrm{D}$, administratively and in combination with each other. The height on the surface must be known to find out whether 3D objects are above, on or under the surface (see Stoter and Oosterom, 2001).

The required queries reflect the actual need of the Kadaster for a 3D cadastre. Examples of queries are:

- which other 3D geo-objects are located on top or under a certain 3D object?

- which surface parcels intersect with a (projection of a) 3D geo-object, or vice versa: which $3 \mathrm{D}$ object intersects with a certain parcel?

- is the owner of the parcel the same as the holder of the 3D object (bare or full owner)?

- what rights are established on surface parcels intersecting with a 3D realworld object? Which subjects (legal persons) possesses these rights?

The needed queries are collected and will be translated into prototype implementations in order to make the design of the 3D cadastral system as optimal as possible.

\section{Solution Applied to CASE}

The described technical solutions for the concept of a 3D cadastre using the hybrid approach can be applied to the case mentioned in section 2. The rights of the building will still be registered by means of the $2 \mathrm{D}$ parcels. Preferably this must be done by rights which make the holder of the object the owner of the object, e.g. by means of a right of building or a condominium right.

A right of long lease (as is used in this example) must be avoided, since this does not assure a permanent right of property on the building.

Apart from the rights on the parcels, the 3D real-world object (whole building) itself is maintained in the DBMS of the Kadaster with spatial and non-spatial attributes as well as the relations between the building and the surface parcels (via rights). The information of the holder is also registered.

In the DBMS of the Kadaster you can find that the concerning rights are associated with a $3 \mathrm{D}$ object and it is possible to retrieve more information on the factual (3D) situation. As was mentioned before, this better accessibility of the registration in complex 3D situations improves the legal security of real estate.

In Figure 6 you can see a VRML presentation of the DBMS that was used to implement the concepts (using the self-made topological model). A 
VRML file can be viewed in any web-browser with a VRML plug-in. You can see the parcel boundaries as well as the contours of buildings which are maintained in the DBMS, as well as the 3D model of the building which is stored as such in the DBMS.

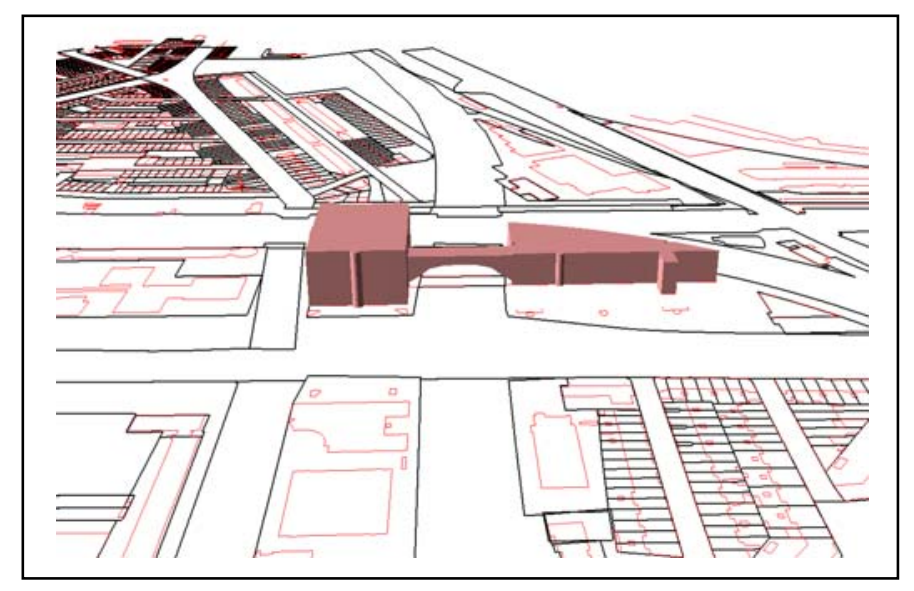

Figure 6: A VRML representation of 2D cadastral data (parcel boundaries and contours of buildings) and a $3 D$ real-world object (building) stored in the DBMS.

\section{CONCLUSION}

There is an increasing interest in using space under and above the surface. In the current cadastral registration system, which is based on 2D parcels, those factual situations are sometimes complicated to maintain. Therefore an urge for a 3D cadastre occurs. In this paper the cadastral needs and ambitions for a 3D cadastre are described. Three possible solutions for a 3D cadastre are given:

- a full 3D cadastre;

- a hybrid system;

- using 3D tags in the current system.

These three solutions have been considered both from a cadastral and technical point of view in order to look for a concept of a feasible 3D cadastre based on cadastral needs and technical possibilities.

In conclusion, a full 3D cadastre might be a solution in the faraway future, when cadastral and technical developments have come far enough. At the moment this solution is too comprehensive. Adding a 3D tag in the current registration has proved to be not sufficient to get insight in the factual situation.

Therefore, we came to a medium-solution: starting with the current 2D cadastral registration and extending this with the possibility to register 3D situations. The technical realisation of this concept is described in this paper. 
Future research will focus on further realisation of the developed concept using prototype implementations, which are based on an integrated $2 \mathrm{D} / 3 \mathrm{D}$ geo-DBMS approach.

\section{ACKNOWLEDGEMENTS}

The authors would like to thank Elfriede Fendel, Auke Hoekstra, Zacharias Klaasse, Peter van Oosterom and Berry van Osch for their review on earlier versions of this paper.

\section{REFERENCES}

Baumgart, B.G. (1975): A polyhedron representation for computer vision, in National Computer Conference, pp. 589-596, 1975.

Doytsher,Y., J.Forrai and G.Kirschner (2001): Initiatives towards a 3D GISrelated multi-layer digital Cadastre in Israel, in proceedings FIG Working Week 2001, Seoul Korea, 6-11 May 2001.

Dutch Civil Code (1992), Civil Code (Burgerlijk Wetboek): Boek 5: Zakelijke Rechten, 1992. (In Dutch)

Kofler, M. (1998): R-trees for the visualisation of large 3D GIS databases, PhD thesis, TU Graz, Austria.

Lemmen, C.H.J., E.P. Oosterbroek and P.M.J. van Oosterom (1998): New spatial data management developments in the Netherlands Cadastre, in proceedings of the FIG XXI International Congress, Brighton UK, Commission 3, Land Information Systems, pp. 398-409, 19-25 July 1998.

Molenaar, M. (1990): A Formal Data Structure for 3D Vector Maps, Proceedings of EGIS'90, Vol. 2, Amsterdam, The Netherlands, pp. 770-781. OGC (2001): OpenGIS specifications, 2001, available on

http://www.opengis.org/techno/specs.htm.

OGC (1999): OpenGIS Simple Features Specification for SQL, revision 1.1, OpenGIS Project Document 99-049.

OGC (1998): The OpenGIS Guide, third edition, An introduction to Interoperable Geo-processing, The OGC Project Technical Committee of the OpenGIS Consortium, edited by Buhler and K. McKee, L., Wayland, Mass., VS.

Oosterom, P.J.M. van and C.H.J. Lemmen (2001): Spatial data management on a very large cadastral database, Computers, Environments and Urban Systems (CEUS), volume 25, number 4-5, pp. 509-528.

Oosterom, P.J.M. van, B. Maessen and W. Quak, (1) (2000): Spatial, thematic and temporal views, 9th International Symposium on Spatial Data Handling, 1012 August 2000, Beijing, China.

Oosterom, P.J.M. van, E. Verbree and A. Kap (2) (2000): Storing and Manipulating Simple and Complex Features in Database Management Systems, in proceedings of the 3rd AGILE Conference on Geographic 
Information Science, Helsinki/Espoo, Finland, pp. 178-182, 25-27 May 2000.

Oracle (2001): Oracle Spatial User's Guide and Reference Release 9.0.1 Part Number A88805-01, June 2001.

Pigot, S. (1995): A Topological Model for a 3-Dimensional Spatial Information System, PhD Thesis, University of Tasmania, Australia, $228 \mathrm{p}$. Pilouk, M. (1996): Integrated Modelling for 3D GIS, PhD thesis, ITC, the Netherlands, 200 p.

Ravi (2000): Privaatrechtelijke aspecten van ondergronds ruimtegebruik, Onderzoek in samenwerking met COB (Centrum Ondergronds Bouwen), RAVI publicatie 00-04, 2000, Amersfoort. (In Dutch)

Saadi Mesgari, M. (2000): Topological Cell-Tuple Structures for ThreeDimensional Spatial Data, PhD thesis, University of Twente and ITC, ITC Dissertation Number 74, Enschede, the Netherlands, 200 p.

Stoter, J.E. (2000): Needs, possibilities and constraints to develop a 3D cadastral registration system, in proceedings of UDMS 2000, 22nd Urban and Regional Data Management Symposium, Delft, the Netherlands, 11-15 September 2000, p. III.43-III.58.

Stoter, J.E. and P.J.M. van Oosterom (2001): Incorporating 3D geo-objects into an existing 2D geo-database: an efficient use of geo-data, in proceedings Geoinformatics and DMGIS? 2001, the $3^{\text {rd }}$ ISPRS Workshop on Dynamic \& Multi-dimensional GIS, the $10^{\text {th }}$ annual conference of CPGIS on Geoinformatics, Asian Institute of Technology, Bangkok, Thailand, 23-25 May 2001.

Stoter, J.E. and J. Zevenbergen (2001): Changes in the definition of property: a consideration for a 3D cadastral registration system, in proceedings FIG Working Week 2001, Seoul Korea, 6-11 May 2001.

Zlatanova, S. (2001): 3D modelling for augmented reality, in proceedings of Geoinformatics and DMGIS 2001, the $3^{\text {rd }}$ ISPRS Workshop on Dynamic \& Multi-dimensional GIS, the $10^{\text {th }}$ annual conference of CPGIS on Geoinformatics, Asian Institute of Technology, Bangkok, Thailand, 23-25 May 2001, pp 415-420.

Zlatanova, S. (2000): 3D GIS for urban development, PhD thesis, ITC publication 69, Enschede, the Netherlands, 222 p. 


\section{ABout THE Authors}

Jantien Stoter (MSc) graduated in Physical Geography in 1994. She started her career as a GIS specialist/consultant, with the District Water Board of Amsterdam and Surroundings (1995-1997). From 1997 till 1999 she worked as a GIS specialist/consultant at the Engineering Office Holland Rail Consult.

Since 1999 she is an assistant professor in GIS applications, section GIS technology, Department of Geodesy, Delft University of Technology

Also doing a Ph.D. on 3D cadastres. In this research the needs, possibilities, and constraints are studied for 3D cadastral registrations. The emphasis of the research is the implementation of the facility to incorporate $3 \mathrm{D}$ real estate objects (geo-objects) in the current 2D geo-DBMS of the Netherlands' Kadaster.

Martin Salzmann heads the geodesy section of the Netherlands' Kadaster. He is involved in consultancy and innovation in the fields of geodesy and geoinformation, the development of the geometric infrastructure of the Netherlands and quality management of cadastral working processes. He has been with the Kadaster since 1996. Martin holds degrees in geodesy. (Msc and $\mathrm{PhD}$ ) of Delft University of Technology.

\section{CONTACT AdDress}

Name:

Institution:

Office address:

Telephone:

Fax:

E-mail:

URL:

Name:

Institution:

Telephone:

Fax:

E-mail:
Drs. Jantien Stoter

Department of Geodesy

Faculty of Civil Engineering and Geosciences

Delft University of Technology

P.O. Box 5030

2600 GA DELFT

The Netherlands

+31152788136

+31152782745

j.e.stoter@citg.tudelft.nl

www.gdmc.nl/stoter

Dr. Martin Salzmann

Kadaster (Cadastre and Public Registers Agency of the

Netherlands)

P.O. Box 9046

7300 GH Apeldoorn

The Netherlands

+31555285507

+31555285036

martin.salzmann@kadaster.nl 